\title{
Experimental Study of Deltamethrin-Induced Nephrotoxicity in the Rat Model
}

\author{
Eugene A. Chigrinski, $\mathrm{PhD}^{1 *}$; Taras V. Gerunov, $\mathrm{PhD}^{2}$; Liudmila K. Gerunova, $\mathrm{PhD}, \mathrm{ScD}^{2}$; \\ Yuri N. Fedorov, $\mathrm{PhD}, \mathrm{ScD}^{3}$; Nikolai V. Shorin, $\mathrm{PhD}^{2}$ \\ ${ }^{I}$ Omsk State Medical University, Omsk, the Russian Federation \\ ${ }^{2}$ Omsk State Agrarian University named after P.A. Stolypin, Omsk, the Russian Federation \\ ${ }^{3}$ All-Russian Research and Technological Institute of Biological Industry, Shchelkovskii District, \\ Moscow Oblast, the Russian Federation
}

\begin{abstract}
The purpose of this study was to determine the nephrotoxic effect of deltamethrin in experimental animals at a dose of $43.5 \mathrm{mg} / \mathrm{kg}(1 / 2 \mathrm{LD} 50)$.

Materials and Methods: For the experiment, 48 male Wistar rats with a body weight of $240 \pm 10 \mathrm{~g}$ were divided into 4 groups of 12 animals each. Groups 1 and 3 were control groups, which were administered a physiological solution intragastrically. The animals in Groups 2 and 4 received a single dose $(43.5 \mathrm{mg} / \mathrm{kg})$ of the synthetic pyrethroid deltamethrin, which corresponds to 1/2 LD50. Rats were withdrawn from the experiment in two stages: 1) rats in Groups 1 and 2 - one day after the deltamethrin administration; 2) rats in Groups 3 and $4-3$ days after the deltamethrin administration. Biochemical and pathomorphological changes in the kidneys were evaluated. The evaluation criteria were the content of pyruvate, inorganic phosphate, and glutathione (GSH) and the activity of glutathione peroxidase activity (GPx), glutathione reductase (GR) and glutathione-S-transferase (GST) in the kidneys. Histological preparations of kidney tissue were studied.

Results: The single administration of a toxic dose of deltamethrin caused a decrease in body weight of rats, an increase in kidney weight, and the accumulation of pyruvate and inorganic phosphate in the kidneys. A decrease in the GSH content was accompanied by an increase in the activity of GPx, GR and GST. One day after the experiment, in the convoluted tubules, epithelial cells with blurred contours of the boundaries were enlarged; and the granularity of the cytoplasm containing vacuoles was expressed. The nuclei of epithelial cells had different sizes; some of them were in a state of pycnosis. In the organ parenchyma, large and small blood vessels full of blood were visible. Three days after the intoxication, these symptoms became more pronounced. In the intertubular connective tissue, hemorrhages and leukocyte infiltrates were detected.

Conclusion: The study confirms the nephrotoxic effect of a single toxic dose (43.5 mg/kg [1/2 LD50]) of deltamethrin. Pathomorphological changes in the kidneys are accompanied by the disturbances in energy metabolism and activation of the glutathione antioxidant system with the development of glutathione deficiency.(International Journal of Biomedicine. 2018;8(3):220-223.)
\end{abstract}

Key Words: pesticides $\bullet$ pyrethroids $\bullet$ deltamethrin $\bullet$ kidney $\bullet$ antioxidant system

\section{Abbreviations}

BW, body weight; GPx, glutathione peroxidase; GR, glutathione reductase; GST, glutathione-S-transferase; GSH, glutathione; KW, kidney weight; KMI, kidney mass index.

\section{Introduction}

Synthetic pyrethroids are used extensively as insecticides and acaricides in agriculture and veterinary medicine, acting as neurotoxic agents. Among pyrethroids, deltamethrin is one of the most popular and widely used insecticides in the world. ${ }^{(1)}$ It is used in agriculture and veterinary medicine for the destruction of pests of plants and ectoparasites of animals. ${ }^{(2)}$ Deltamethrin plays a key role in controlling malaria vectors and preventing the spread of diseases carried by ticks. ${ }^{(3-5)}$ This pesticide is highly toxic to aquatic life, particularly fish, and therefore must be used with extreme caution around water. Deltamethrin ${ }^{(1,6,7)}$ is highly 
toxic to humans and other mammals.In recent years, however, a number of studies have been published demonstrating pathologically proven motor neuron death in people after acute, massive ingestion of pesticides containing pyrethroids. ${ }^{(8-10)}$ The effect of deltamethrin on different organs and systems has also been described. ${ }^{(11-14)}$ In this connection, there is an increasing interest in studying its toxicity for animals and humans.

The purpose of this study was to determine the nephrotoxic effect of deltamethrin in experimental animals at a dose of $43.5 \mathrm{mg} / \mathrm{kg}(1 / 2 \mathrm{LD} 50)$.

\section{Materials and Methods}

For the experiment, 48 male Wistar rats with a body weight of $240 \pm 10 \mathrm{~g}$ were divided into 4 groups of 12 animals each. Groups 1 and 3 were control groups, which were administered a physiological solution intragastrically. The animals in Groups 2 and 4 received a single dose $(43.5 \mathrm{mg} / \mathrm{kg})$ of the synthetic pyrethroid deltamethrin, which corresponds to $1 / 2$ LD50. Rats were withdrawn from the experiment in two stages: 1) rats in Groups 1 and 2 - one day after the deltamethrin administration; 2) rats in Groups 3 and $4-3$ days after the deltamethrin administration.

In the course of the experiment, the preparative form of deltamethrin was used under the trade name "Butox 50" (Intervet Productions SA, France). All stages of the experiment were carried out in accordance with the requirements of Directive 2010/63/EU of the European Parliament and of the Council of 22 September 2010 on the protection of animals used for scientific purposes.

At the final stage of the experiment, the rats were weighed. Kidneys of the animals were removed and weighed. The right kidneys were homogenized at $0-2^{\circ} \mathrm{C}$ and biochemical markers were determined in the resulting homogenate. The content of total protein, pyruvate and inorganic phosphate was determined by unified methods. The GSH level was determined according to Rousar et al. ${ }^{(15)}$ the activity of GPx and GR according to Vlasova et al. ${ }^{(16)}$, and GST according to Habig and Jakoby. ${ }^{(17)}$

For histological examination, the pieces of kidney tissue (the middle third of the left kidney) from each rat were fixed in a $4 \%$ neutral solution of formaldehyde, dehydrated in spirits with increasing concentration, then poured into paraffin. On a rotary microtome, tissue sections of $5 \mu \mathrm{m}$ thick were made and stained with hematoxylin and eosin. The study of histological preparations was carried out using the Altami BIO 1 microscope (Altami, Russia).

Statistical analysis was performed using the statistical software «Statistica» (v6.0, StatSoft, USA). The results are presented as $\mathrm{Me}$ (median), Q1 (lower quartile), and Q3 (upper quartile). The Mann-Whitney (U Test) was used to compare the differences between the two independent groups. A probability value of $P<0.05$ was considered statistically significant.

\section{Results}

We recorded a decrease in $\mathrm{BW}$ of rats as a result of exposure to a toxic dose of deltamethrin (Table 1). This change was observed both in the first and third days of the experiment.
An opposite trend was observed in the change in the mass of the kidneys of experimental animals. A decrease in BW and an increase in the mass of the kidneys led to an increase in KMI (Table 1).

Table 1.

$B W$ of rats and KMI after after a single deltamethrin administration at a dose of $1 / 2$ LD50

\begin{tabular}{|c|c|c|c|}
\hline Group & BW, g & KW, g & KMI, g/100 g \\
\hline \multicolumn{4}{|c|}{ Day 1 } \\
\hline Group 1 & $240(239-248)$ & $0.740(0.700-0.817)$ & $0.304(0.288-0.341)$ \\
\hline Group 2 & $\begin{array}{c}237(231-241) \\
P=0.0223\end{array}$ & $\begin{array}{c}0.905(0.878-1.070) \\
P=0.0003\end{array}$ & $\begin{array}{c}0.393(0.369-0.456) \\
P=0.0001\end{array}$ \\
\hline \multicolumn{4}{|c|}{ Day 3 } \\
\hline Group 3 & $\begin{array}{c}244(240-248) \\
0.704(0.654-0.776)\end{array}$ & $0.291(0.272-0.314)$ \\
\hline Group 4 & $\begin{array}{c}234(233-242) \\
P=0.0050\end{array}$ & $\begin{array}{c}0.995(0.950-1.14) \\
P=0.0003\end{array}$ & $\begin{array}{c}0.420(0.403-0.492) \\
P=0.0002\end{array}$ \\
\hline
\end{tabular}

The single administration of a toxic dose of deltamethrin caused the accumulation of pyruvate and inorganic phosphate in the kidneys (Table 2). A day after the beginning of the experiment, the median value for pyruvate and inorganic phosphate increased by $29.7 \%$ and $39.7 \%$, on the third day - by $24.1 \%$ and $116 \%$, respectively, compared to the control.

Much attention in the studies of pesticide-related intoxications is devoted to determining the antioxidant system parameters. ${ }^{(11,12,18)}$ Of greatest interest, in our opinion, is the study of GSH, since GSH not only enters into battle with free radicals and products of lipoperoxidation, but also participates in the reactions of conjugation of synthetic pyrethroids. ${ }^{(19,20)}$ In our experiment, there was a decrease in the content of GSH in the kidneys of rats subjected to a single deltamethrin administration (Table 2).

Table 2.

The content of pyruvate, inorganic phosphate (Pi), and GSH in the kidneys of rats after after a single deltamethrin administration at a dose of 1/2 LD50

\begin{tabular}{|c|c|c|c|}
\hline Group & Pyruvate, $\mu \mathrm{mol} / \mathrm{g}$ & $\mathrm{Pi}, \mu \mathrm{mol} / \mathrm{g}$ & $\begin{array}{c}\mathrm{GSH}, \mathrm{nmol} / \mathrm{mg} \\
\text { protein }\end{array}$ \\
\hline \multicolumn{4}{|c|}{ Day 1} \\
\hline Group 1 & $0.431(0.410-0.462)$ & $5.56(4.19-7.32)$ & $30.8(24.9-32.2)$ \\
\hline Group 2 & $\begin{array}{c}0.559(0.490-0.601) \\
P=0.0032\end{array}$ & $\begin{array}{c}7.77(6.25-9.24) \\
P=0.0209\end{array}$ & $\begin{array}{c}18.8(17.6-24.3) \\
P=0.0005\end{array}$ \\
\hline \multicolumn{4}{|c|}{ Day 3 } \\
\hline Group 3 & $0.440(0.407-0.510)$ & $4.56(3.58-7.06)$ & $29.1(26.0-33.1)$ \\
\hline Group 4 & $\begin{array}{c}0.546(0.479-0.620) \\
P=0.0056\end{array}$ & $\begin{array}{c}9.83(8.17-12.18) \\
P=0.0002\end{array}$ & $\begin{array}{c}20.7(18.8-26.2) \\
P=0.0015\end{array}$ \\
\hline
\end{tabular}

A decrease in the GSH content in the kidney was accompanied by activation of enzymes of its metabolism (Table 3). GPx activity increased by $73.4 \%$ and $42.2 \%$ on the first and third days of the experiment, respectively. GR activity increased by $82.9 \%$ and $81.5 \%$ on the first day and the third day, respectively. 
Table 3.

The activity of glutathione-dependent enzymes in the kidneys of rats after a single deltamethrin administration at a dose of 1/2 LD50

\begin{tabular}{|c|c|c|c|}
\hline Group & $\begin{array}{c}\text { GPx, } \\
\text { U/mg protein }\end{array}$ & $\begin{array}{c}\text { GR, } \\
\text { U/mg protein }\end{array}$ & $\begin{array}{c}\text { GST, } \\
\text { U/mg protein }\end{array}$ \\
\hline \multicolumn{4}{|c|}{ Day 1 } \\
\hline Group 1 & $504(446-647)$ & $299(252-368)$ & $373(345-474)$ \\
\hline Group 2 & $\begin{array}{c}874(598-958) \\
P=0.0043\end{array}$ & $\begin{array}{c}547(452-634) \\
P=0.0001\end{array}$ & $\begin{array}{c}726(635-793) \\
P<0.0001\end{array}$ \\
\hline \multicolumn{4}{|c|}{ Day 3 } \\
\hline Group 3 & $578(465-610)$ & $248(230-349)$ & $414(352-455)$ \\
\hline Group 4 & $\begin{array}{c}822(674-923) \\
P=0.0001\end{array}$ & $\begin{array}{c}450(354-564) \\
P=0.0010\end{array}$ & $\begin{array}{c}607(573-672) \\
P=0.0001\end{array}$ \\
\hline
\end{tabular}

Although the total GST activity in the kidneys is lower than in the liver, renal GST also promotes the formation of conjugates with degradation products of deltamethrin. A single deltamethrin administration at a dose of 1/2 LD50 led to an increase in GST activity in kidneys by $94.6 \%$ after the first day of the experiment. On the third day of the experiment, the GST activity remained quite high (Table 3 ).

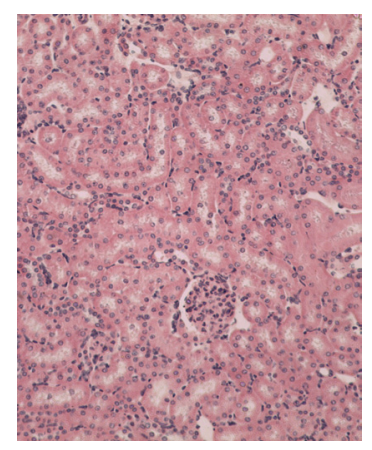

(a)

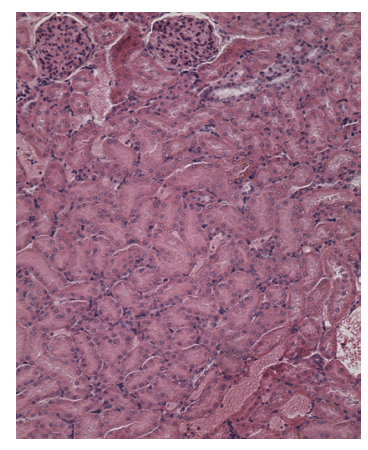

(b)

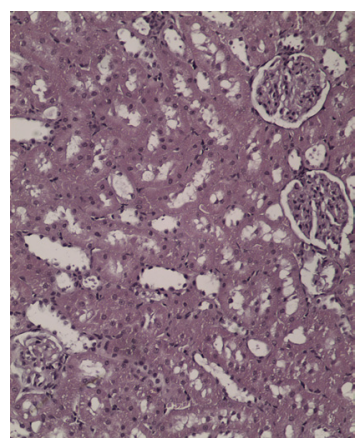

(c)
Fig. 1.

Light microscopy of the kidneys of rats. Control (a), 24 hours (b) and 72 hours (c) after a single deltamethrin administration at a dose of $1 / 2$ LD50 $(43.5 \mathrm{mg} / \mathrm{kg})$. Hematoxylin Eosin staining.

(a) The size of the glomeruli is unchanged, small subcapsular spaces, epithelium of the renal tubules without damage.

(b) The granularity of the cytoplasm of renal tubule epithelial cells, narrowing of lumen of proximal tubules, congestive hyperemia.

(c) Cytoplasmic vacuoles in renal tubule epithelial cells.
During the histological examination, we found the following changes (Figure 1): One day after the experiment, in the convoluted tubules, epithelial cells with blurred contours of the boundaries were enlarged; and the granularity of the cytoplasm containing vacuoles was expressed. The nuclei of epithelial cells had different sizes; some of them were in a state of pycnosis. In individual cells, the diameter of the nuclei was increased in comparison with the control. Some vascular glomeruli were hyperemic. In the organ parenchyma, large and small blood vessels full of blood were visible. Three days after the intoxication, these symptoms became more pronounced. Degenerative processes in the epithelial cells of tubules increased; therefore, the number of fragments of desquamated cells increased in the tubular lumen, and the lumen of the tubules was narrowed. The intensity of vacuolization of the cytoplasm on different sites of histological specimens was expressed in different degrees. In the intertubular connective tissue, hemorrhages and leukocyte infiltrates were detected. On the control histological specimens, various sections of the renal tubules and glomeruli were observed, surrounded by a capsule, without pathological changes.

\section{Discussion}

An increase in the mass of the kidneys may indicate the active inclusion of these organs in clearing and removing deltamethrin and its metabolites from the bodies of rats. To activate metabolism and neutralize deltamethrin in the kidneys, a large amount of energy is needed. However, the accumulation of pyruvate, noted above, indicates a disturbance of aerobic oxidation, probably due to inhibition of the tricarboxylic acid cycle. This assumption is confirmed by an increase in the concentration of inorganic phosphate in the kidneys of rats in the early stages of acute poisoning with deltamethrin. The source of a large number of phosphoric acid residues can be the active catabolism of the purine and pyrimidine mono-, diand triphosphates. ${ }^{(21)}$

The increased burden on the glutathione system of the kidneys after deltamethrin administration promotes the activation of enzymes of its metabolism, probably due to activation of the antioxidant response element (ARE). ${ }^{(22,23)}$ ARE induces the synthesis of GP and GR, which function in close cooperation and contribute to providing the glutathione redox cycle. In itself, the use of GSH in these two reactions does not lead to GSH deficiency. However, there are a number of enzymes that extract GSH from this cycle and irreversibly attach GSH or its individual amino acids to various substrates, in particular, to deltamethrin decay products. Such enzymes include GST; we noted its activation in the kidneys of rats after acute poisoning. GST, along with GP and GR, is an enzyme whose gene is regulated by ARE. ${ }^{(22)}$

After the action of GST and associated enzymes, GSH breaks down into constituent amino acids. For the re-synthesis of GSH, the energy of ATP is required, the availability of which is limited by the inhibition of the cycle of tricarboxylic acids and the mitochondrial respiratory chain. This can contribute to the development of GSH deficiency and ultimately disrupt the functioning of the glutathione system of the kidneys. 
The described biochemical changes also have morphological manifestations. Our study demonstrates that under the simulated conditions, free radical processes are activated. Active oxygen metabolites can be produced by both kidney cells and immune system cells. ${ }^{(24,25)}$ The reactive oxygen species themselves are capable of provoking and stimulating the development of destructive processes. ${ }^{(26)}$

Moreover, lesions can occur in different parts of nephrons (glomeruli, renal tubules, vessels) and induce necrosis or apoptosis. ${ }^{(27)}$

Thus, our study confirms the nephrotoxic effect of a single toxic dose $(43.5 \mathrm{mg} / \mathrm{kg}$ [1/2LD50]) of deltamethrin. Pathomorphological changes in the kidneys are accompanied by the disturbances in energy metabolism and activation of the glutathione antioxidant system with the development of glutathione deficiency.

\section{Competing interests}

The authors declare that they have no competing interests.

\section{References}

1. PubChem: Deltamethrin. Available from: https://pubchem. ncbi.nlm.nih.gov/compound/deltamethrin\#section=Top

2. Katsuda Y. Progress and future of pyrethroids. Top Curr Chem. 2012;314:1-30. doi: 10.1007/128 2011252

3. Kurek M, Barchańska H, Turek M. Degradation Processes of Pesticides Used in Potato Cultivations. Rev Environ Contam Toxicol. 2017;242:105-51. doi: 10.1007/398_2016_13.

4. Bradberry SM, Cage SA, Proudfoot AT, Vale JA. Poisoning due to pyrethroids. Toxicol Rev. 2005;24(2):93-106.

5. Vais H, Williamson MS, Devonshire AL, Usherwood PN. The molecular interactions of pyrethroid insecticides with insect and mammalian sodium channels. Pest Manag Sci. 2001;57(10):877-88.

6. Shafer TJ, Meyer DA, Crofton KM. Developmental neurotoxicity of pyrethroid insecticides: critical review and future research needs. Environ Health Perspect. 2005. 113(2):123-36.

7. Soderlund DM, Clark JM, Sheets LP, Mullin LS, Piccirillo VJ, Sargent D, et al. Mechanisms of pyrethroid neurotoxicity: implications for cumulative risk assessment. Toxicology. 2002;171(1):3-59.

8. Taguchi S, Shimizu K, Yokote R, Uchiyama M, Sekii H, Kiyota K. [Three cases of inhalation of household pyrethroid and metoxadiazone insecticides with remarkable dyspnea]. Chudoku Kenkyu. 2006;19(2):147-53. [Article in Japanese]. 9. Magdalan J, Zawadzki M, Merwid-Lad A. Fatal intoxication with hydrocarbons in deltamethrin preparation. Hum Exp Toxicol. 2009;28(12):791-3. doi: 10.1177/0960327109354939.

10. Gunay N, Kekec Z, Cete Y, Eken C, Demiryurek AT. Oral deltamethrin ingestion due in a suicide attempt. Bratisl Lek Listy. 2010;111(5):303-5.

*Corresponding author: Eugene A. Chigrinski, PhD. Department of Biochemistry, Omsk State Medical University. Omsk, Russia. E-mail: chigrinski@list.ru
11. Sharma P, Singh R, Jan M. Dose-dependent effect of deltamethrin in testis, liver, and kidney of wistar rats. Toxicol Int. 2014. 21(2):131-9. doi: 10.4103/0971-6580.139789.doi: 10.4103/0971-6580.139789.

12. Nieradko-Iwanicka B, Borzecki A. How Deltamethrin Produces Oxidative Stress in Liver and Kidney. Pol J Environ Stud. 2016;25(3):1367-71. doi: 10.15244/pjoes/61818.

13. Issam C, Samir H, Zohra H, Monia Z, Hassen BC. Toxic responses to deltamethrin (DM) low doses on gonads, sex hormones and lipoperoxidation in male rats following subcutaneous treatments. J Toxicol Sci. 2009;34(6):663-70. doi: $10.2131 /$ jts.34.663.

14. Khalatbary AR, Ghabaee DNZ, Ahmadvand H, Amiri FT, Lehi ST. Deltamethrin-Induced Hepatotoxicity and Virgin Olive Oil Consumption: An Experimental Study. Iran J Med Sci. 2017;42(6):586-592.

15. Rousar T, Kucera O, Lotkova H, Cervinkova Z. Assessment of reduced glutathione: comparison of an optimized fluorometric assay with enzymatic recycling method. Anal Biochem. 2012;423(2):236-40. doi: 10.1016/j. ab.2012.01.030

16. Vlasova SN, Shabunina EI, Pereslegina IA. [The activity of the glutathione-dependent enzymes of erythrocytes in chronic liver diseases in children]. Lab Delo. 1990;8:19-22. [Article in Russian].

17. Habig WH, Jakoby WB. Glutathione S-transferases (rat and human). Methods Enzymol. 1981;77:218-31.

18. Saoudi M, Badraoui R, Bouhajja H, Ncir M, Rahmouni F, Grati M, et al. Deltamethrin induced oxidative stress in kidney and brain of rats: Protective effect of Artemisia campestris essential oil. Biomed Pharmacother. 2017;94:955-63. doi: 10.1016/j.biopha.2017.08.030.

19. Villarini M, Moretti M, Scassellati-Sforzolini G, Monarca S, Pasquini R, Crea MG et al. Studies on hepatic xenobioticmetabolizing enzymes in rats treated with insecticide deltamethrin. J Environ Pathol Toxicol Oncol. 1995;14(1):4552.

20. Yousef MI, Awad TI, Mohamed EH. Deltamethrin-induced oxidative damage and biochemical alterations in rat and its attenuation by Vitamin E. Toxicology. 2006;227(3):240-7.

21. Buhl MR. Purine metabolism in ischemic kidney tissue. Dan Med Bull. 1982;29(1):1-26.

22. Lyakhovich VV, Vavilin VA, Zenkov NK, Menshchikova EB. Active defense under oxidative stress. The antioxidant responsive element. Biochemistry (Mosc). 2006;71(9):962-74. 23. Li H, Wu S, Chen J, Wang B, Shi N. Effect of glutathione depletion on Nrf2/ARE activation by deltamethrin in PC12 Cells. Arh Hig Rada Toksikol. 2013;64(1):87-97. doi: 10.2478/10004-1254-64-2013-2251.

24. Farber JL, Kyle ME, Coleman JB. Mechanisms of cell injury by activated oxygen species. Lab Invest. 1990;62(6):670-9.

25. Sedor JR, Carey SW, Emancipator SN. Immune complexes bind to cultured rat glomerular mesangial cells to stimulate superoxide release. Evidence for an Fc receptor. J Immunol. 1987;138(11):3751-7.

26. Mittal M, Siddiqui MR, Tran K, Reddy SP, Malik AB. Reactive oxygen species in inflammation and tissue injury. Antioxid Redox Signal. 2014;20(7):1126-67. doi: 10.1089/ ars.2012.5149

27. Ratliff BB, Abdulmahdi W, Pawar R, Wolin MS. Oxidant Mechanisms in Renal Injury and Disease. Antioxid Redox Signal. 2016;25(3):119-46. doi: 10.1089/ars.2016.6665. 